\title{
DO FIRMS SMOOTH THE \\ SEASONAL IN PRODUCTION IN \\ A BOOM? THEORY AND EVIDENCE
}

\author{
Stephen G. Cecchetti \\ Anil K. Kashyap \\ David W. Wilcox
}

Working Paper No. 5011

\author{
NATIONAL BUREAU OF ECONOMIC RESEARCH \\ 1050 Massachusetts Avenue \\ Cambridge, MA 02138 \\ February 1995
}

We would like to thank Michael Woodford for very useful conversations, as well as Andrew Abel, William Bell, Mark Bils, William Cleveland, Stephen Cosslett, Spencer Krane, Pok-sang Lam, Jeffrey Miron, Nelson Mark, Mark Watson, Alan Viard, and participants at numerous seminars for comments and suggestions. Donald Andrews generously supplied the GAUSS programs used to perform some of the reported calculations. Cecchetti and Kashyap acknowledge the financial support of the National Science Foundation, and research support of the Federal Reserve Banks of Cleveland and Chicago respectively. This paper is part of NBER's research programs in Economic Fluctuations and Monetary Economics. Any opinions expressed are those of the authors and not those of the National Bureau of Economic Research.

(c) 1995 by Stephen G. Cecchetti, Anil K. Kashyap and David W. Wilcox. All rights reserved. Short sections of text, not to exceed two paragraphs, may be quoted without explicit permission provided that full credit, including $\odot$ notice, is given to the source. 
February 1995

\title{
DO FIRMS SMOOTH THE \\ SEASONAL IN PRODUCTION IN \\ A BOOM? THEORY AND EVIDENCE
}

\begin{abstract}
Using disaggregated production data we show that the size of seasonal cycles changes significantly over the course of the business cycle. In particular, during periods of high economy-wide activity, some industries smooth seasonal fluctuations while others exaggerate them. We interpret this finding using a simple analytical model that describes the conditions under which seasonal and cyclical fluctuations can be separated. Our model implies that seasonal fluctuations can safely be disentangled from cyclical fluctuations only when the marginal cost of production is linear, and the variation in demand and cost satisfy certain (restrictive) conditions. The model also suggests that inventory movements can be used to isolate the role of demand shifts in generating any interaction between seasonal cycles and business cycles.

Thus, the empirical analysis involves studying the variation in seasonally unadjusted patterns of production and inventory accumulation over different phases of the business cycle. Our finding that seasonals shrink during booms and that firms carry more inventories into high sales seasons during a boom leads us to conclude that for several industries, marginal cost slopes up at an increasing rate. Conversely, in a couple of industries we find that seasonal swings in production are exaggerated during booms and that inventories are drawn down prior to high sales seasons, suggesting that marginal costs curves flatten as production increases. Overall, we find considerable evidence that there are non-linear interactions between business cycles and seasonal cycles.
\end{abstract}

Stephen G. Cecchetti Department of Economics Boston College Chestnut Hill, MA 02167 and NBER
Anil K. Kashyap

Graduate School of Business

University of Chicago

1101 E 58th Street

Chicago, IL 60637

and NBER
David W. Wilcox

Division of Monetary Affairs

Board of Governors of the Federal Reserve

Washington, DC 20551 


\section{Introduction and Motivation}

A growing literature examines the shape of the aggregate production function. Recently, the orthodox view that marginal cost curves are upward-sloping has been attacked by Hall (1991) and Ramey (1991), who argue that a number of important macroeconomic phenomena are consistent with declining marginal costs, i.e. increasing returns to scale or agglomeration economies. This paper develops new evidence on the shape of the production function based on changes in the seasonal pattern of production over the business cycle.

We find that in several industries, the seasonal in production is smaller during booms and that firms carry more inventories into high sales seasons during a boom. In a few other industries, however, we find that the seasonal in production is exaggerated during booms and that inventories are drawn down more prior to high sales seasons, suggesting that marginal cost curves flatten, creating incentives to bunch production. Overall, we find considerable evidence that there are non-linear interactions between business cycles and seasonal cycles.

To help interpret this evidence, we present a simple analytical model of production decisions in the face of demand and costs that fluctuate both seasonally and cyclically. The model suggests that inventory movements of the type we observe are revealing for the shape of the cost function. The model also has implications for seasonal adjustment. In particular, seasonal fluctuations can be disentangled from cyclical fluctuations only when the marginal cost of production is linear and the variations in demand and cost satisfy certain (restrictive) conditions.

This work builds on that of Barsky and Miron (1989), Beaulieu and Miron (1991 and 1992), Krane (1993), and Miron and Zeldes (1988 and 1989) all of whom use information on seasonal cycles to provide insights into economic behavior; Blanchard (1983), West (1986), Krane and Braun (1991), Fair (1989) and Kashyap and Wilcox (1993) who analyze the cost structure of production; Ghysels (1991), who documents the statistical asymmetries in seasonal fluctuations; and Blinder (1986), and Blinder and Maccini (1991), who study inventories and production smoothing. ${ }^{1}$

\footnotetext{
${ }^{1}$ West's (1990) work using inventory fluctuations to distinguish supply from demand shocks is also related.
} 
Our work is closest to that of Beaulieu, Mackie-Mason and Miron (1992), who suggest that capacity constraints can change the nature of the seasonal variation in output. We view their finding as complementary to ours. An important distinguishing feature of our effort is that our model allows us to catalogue the conditions under which cyclical and seasonal variation are related, and shows how to use these interactions to learn about the shape of industry cost curves.

The remainder of this paper is divided into four sections. The next section establishes the basic stylized facts that we seek to explain. Section 3 presents a model of the production decisions of monopolistically competitive firms that can be used to interpret these facts. Section 4 presents a more focused investigation of the data, and the final section contains our conclusions.

\section{Basic Facts About the Links Between Business and Seasonal Cycles}

Real-time analysis of the detailed components of industrial production suggests that interactions between seasonal and cyclical shifts are quite common. One example of such an interaction comes from the recent experience of firms in the paper and pulp industry. Near the end of the expansion of the 1980s, not seasonally adjusted (NSA) data showed that the industry was operating continuously at very high rates of capacity utilization. But, because production had fluctuated seasonally in the past, the reported seasonally adjusted (SA) numbers showed variation in output. In particular, there were reported declines in SA output during the typically-highproduction months. ${ }^{2}$

To demonstrate the impact of cycles on seasonals, we calculate the differences in the seasonal component of production between high and low points of the business cycle. Define three indicator variables: $I_{t}^{h}$ for 'high' levels of activity, $I_{t}^{\ell}$ for 'low'

\footnotetext{
${ }^{2}$ This example is consistent with Beaulieu, Mackie-Mason and Miron's (1992) observation that capacity constraints could affect seasonality.
} 
levels of activity, and $I_{t}^{n}$ for 'normal' levels of activity, such that

$$
I_{t}^{h}=\left\{\begin{array}{cc}
1 & \text { if } \lambda_{t}>\lambda_{h} \\
0 & \text { otherwise }
\end{array} \quad, \quad I_{t}^{\ell}=\left\{\begin{array}{cc}
1 & \text { if } \lambda_{t}<\lambda_{\ell} \\
0 & \text { otherwise }
\end{array}\right.\right.
$$

and $I_{t}^{n}=1-I_{t}^{h}-I_{t}^{\ell}$, where $\lambda_{t}$ is a (stationary) measure of aggregate economic activity, and $\lambda_{h}$ and $\lambda_{\ell}$ are the high and low threshold levels for $\lambda_{t}$.

Now consider regressing production on seasonal dummy variables interacted with each of the indicator variables:

$$
q_{t}-\bar{q}_{t}=\sum_{i=1}^{12} b_{i}^{h} s_{i t} I_{t}^{h}+\sum_{i=1}^{12} b_{i}^{n} s_{i t} I_{t}^{n}+\sum_{i=1}^{12} b_{i}^{\ell} s_{i t} I_{t}^{\ell}+u_{t}
$$

where $q_{t}$ is the $\log$ of industry output, $s_{i t}$ is a dummy variable that takes on the value 1 in season $i$ and 0 otherwise, and $\bar{q}_{t}$ is a measure of trend output in the industry we use the twelve-month centered moving average of $q_{t}{ }^{3}{ }^{3}$ If $b_{i}^{h}=b_{i}^{n}=b_{i}^{\ell}$, then (2) simplifies to the standard model of fixed seasonality. We, of course, are interested in the possibility that the $b$ 's differ across states of the business cycle.

As a crude method of assessing the importance of any such differences, we compute the ratio of the variance of the $b_{i}^{h}$ 's to the variance of the $b_{i}^{\ell}$ s:

$$
\mathcal{R}\left(\lambda_{\ell}, \lambda_{h}\right)=\frac{\operatorname{Var}\left(b_{i}^{h}\right)}{\operatorname{Var}\left(b_{i}^{\ell}\right)}
$$

We interpret values of $\mathcal{R}$ that are less than 1 as indicating that the amplitude of seasonal variations in output is less when aggregate activity is high. We measure the state of the business cycle, $\lambda_{t}$, using seasonally adjusted capacity utilization in manufacturing lagged one month with its seasonal means removed. ${ }^{4}$

\footnotetext{
${ }^{3}$ The use of a twelve-month moving average has the advantages that the estimated $\bar{q}_{t}$ will not have any fixed seasonal component in it, and that even if $q_{t}$ has a unit root, $\left(q_{t}-\bar{q}_{t}\right)$ will be stationary. While we could choose any moving average with span equal to a multiple of the seasonal frequency of the data, choices longer than twelve tend to de-emphasize the movements in the seasonals relative to movements away from the 'trend.'

${ }^{4}$ We use lagged capacity utilization to emphasize that it is responses to predictable aggregate fluctuations that are important for these measurements. This point is discussed in more detail in Section 3 below. But since the series is so highly autocorrelated, the use of contemporaneous values has virtually no impact on the results.
} 
Table 1: Ratio of the Variance of Seasonal Means During Periods of High Levels of Activity to the Variance of Seasonal Means During Low Levels of Activity, Monthly 2-Digit Industrial Production, 1956:01 to 1994:01

\begin{tabular}{|c|c|c|c|c|c|c|c|c|c|}
\hline $\begin{array}{c}\text { (1) } \\
\text { Industry }\end{array}$ & $\begin{array}{c}(2) \\
\mathcal{R}(50,50)\end{array}$ & $\begin{array}{c}(3) \\
\mathcal{R}(15,85)\end{array}$ & $\begin{array}{c}(4) \\
\text { Test for } \\
\text { equality of } \\
b^{\ell} \text { and } b^{h}\end{array}$ & $\begin{array}{c}(5) \\
\text { Variance } \\
\text { due to } \\
\text { Seasonality }\end{array}$ & $\begin{array}{c}(6) \\
\text { Industry }\end{array}$ & $\begin{array}{c}(7) \\
\mathcal{R}(50,50)\end{array}$ & $\begin{array}{c}(8) \\
\mathcal{R}(15,85)\end{array}$ & $\begin{array}{c}(9) \\
\text { Test for } \\
\text { equality of } \\
b^{\ell} \text { and } b^{h}\end{array}$ & $\begin{array}{c}(10) \\
\text { Variance } \\
\text { due to } \\
\text { Seasonality }\end{array}$ \\
\hline 20 Foods & $\begin{array}{c}0.83 \\
(-1.50)\end{array}$ & $\begin{array}{c}0.74 \\
(-1.98)\end{array}$ & 0.08 & 0.91 & 30 Rubber & $\begin{array}{c}1.25 \\
(0.70)\end{array}$ & $\begin{array}{c}0.98 \\
(-0.09)\end{array}$ & 0.01 & 0.48 \\
\hline 21 Tobacco & $\begin{array}{c}0.75 \\
(-2.57)\end{array}$ & $\begin{array}{c}0.73 \\
(-1.28)\end{array}$ & 0.01 & 0.84 & 31 Leather & $\begin{array}{c}1.24 \\
(0.83)\end{array}$ & $\begin{array}{c}1.07 \\
(0.46)\end{array}$ & 0.00 & 0.67 \\
\hline 22 Textiles & $\begin{array}{c}0.97 \\
(-0.19)\end{array}$ & $\begin{array}{c}0.87 \\
(-0.81)\end{array}$ & 0.00 & 0.76 & $\begin{array}{r}32 \text { Clay, Glass } \\
\text { and Stone }\end{array}$ & $\begin{array}{c}0.99 \\
(-0.06)\end{array}$ & $\begin{array}{c}0.79 \\
(-0.82)\end{array}$ & 0.00 & 0.81 \\
\hline 23 Apparel & $\begin{array}{l}1.43 \\
(2.07)\end{array}$ & $\begin{array}{c}1.25 \\
(1.05)\end{array}$ & 0.00 & 0.82 & $\begin{array}{r}33 \text { Primary } \\
\text { Metals }\end{array}$ & $\begin{array}{l}1.25 \\
(0.53)\end{array}$ & $\begin{array}{c}0.71 \\
(-1.08)\end{array}$ & 0.11 & 0.32 \\
\hline 24 Lumber & $\begin{array}{c}0.87 \\
(-0.68)\end{array}$ & $\begin{array}{c}0.55 \\
(-2.33)\end{array}$ & 0.00 & 0.76 & $\begin{array}{c}34 \text { Fabricated } \\
\text { Metals }\end{array}$ & $\begin{array}{c}0.66 \\
(-1.42)\end{array}$ & $\begin{array}{c}0.58 \\
(-1.18)\end{array}$ & 0.00 & 0.40 \\
\hline 25 Furniture & $\begin{array}{c}1.18 \\
(0.82)\end{array}$ & $\begin{array}{c}1.22 \\
(0.93)\end{array}$ & 0.00 & 0.57 & $\begin{array}{c}35 \text { Nonelectrical } \\
\text { Machinery }\end{array}$ & $\begin{array}{c}0.73 \\
(-0.80)\end{array}$ & $\begin{array}{c}1.23 \\
(0.60)\end{array}$ & 0.00 & 0.32 \\
\hline 26 Paper & $\begin{array}{c}1.06 \\
(0.32)\end{array}$ & $\begin{array}{c}0.69 \\
(-2.65)\end{array}$ & 0.00 & 0.78 & $\begin{array}{l}36 \text { Electrical } \\
\text { Machinery }\end{array}$ & $\begin{array}{l}1.78 \\
(2.06)\end{array}$ & $\begin{array}{c}1.97 \\
(1.82)\end{array}$ & 0.00 & 0.61 \\
\hline 27 Printing & $\begin{array}{c}1.07 \\
(0.29)\end{array}$ & $\begin{array}{c}1.35 \\
(1.03)\end{array}$ & 0.00 & 0.77 & 37 Transportation & $\begin{array}{c}1.89 \\
(2.23)\end{array}$ & $\begin{array}{c}3.59 \\
(4.14)\end{array}$ & 0.06 & 0.47 \\
\hline 28 Chemicals & $\begin{array}{c}0.80 \\
(-0.87)\end{array}$ & $\begin{array}{c}0.70 \\
(-2.19)\end{array}$ & 0.00 & 0.56 & 38 Instruments & $\begin{array}{c}0.88 \\
(-0.52)\end{array}$ & $\begin{array}{c}0.97 \\
(-0.11)\end{array}$ & 0.00 & 0.50 \\
\hline 29 Petroleum & $\begin{array}{c}0.78 \\
(-1.19)\end{array}$ & $\begin{array}{c}0.59 \\
(-1.60)\end{array}$ & 0.03 & 0.72 & 39 Miscellaneous & $\begin{array}{c}1.10 \\
(0.49)\end{array}$ & $\begin{array}{c}0.79 \\
(-1.31)\end{array}$ & 0.00 & 0.73 \\
\hline
\end{tabular}

Columns $2,3,7$ and 8 report estimates of $\mathcal{R}\left(\lambda_{\ell}, \lambda_{h}\right)$. The numbers in parentheses are t-ratios for the hypothesis that $\operatorname{Var}\left(b_{i}^{h}\right)=\operatorname{Var}\left(b_{i}^{\ell}\right)$, where the standard error of the ratio is calculated using the delta method and the Newey-West covariance matrix (with 24 lags) for the vector of the $b^{h}$ 's and the $b^{\ell}$ 's. Columns 4 and 9 report the p-value for the test that all of the $b_{i}^{h}$ 's equal all of the $b_{i}^{\ell}$ 's, when $\lambda^{h}=\lambda^{\ell}$ equal the 50th percentile of the data. Columns 5 and 10 of the table report to $R^{2}$ of the regression of $q_{t}-\bar{q}_{t}$ on seasonal dummy variables. For SIC \#37, Transportation, September through December of 1970 are omitted from the sample to avoid any contamination of the seasonal from the UAW strike. The Apparel series suffered a discontinuity in the source data at the end of 1976; therefore, for that industry we use only the data up through 1976:12. 
Table 1 reports estimates of $\mathcal{R}$ for the 20 two-digit manufacturing industries. We report results for two $\left(\lambda_{h}, \lambda_{\ell}\right)$ pairs. The first sets $\lambda_{h}$ and $\lambda_{\ell}$ both equal to the median value for $\lambda_{t}$ in the data, so $I_{t}^{n} \equiv 0$; these results are reported in the column labeled 'R(50,50).' The second sets $\lambda_{h}$ equal to the 85 th percentile of $\lambda_{t}$ and $\lambda_{\ell}$ equal to the 15 th percentile; these results are reported in the column labeled ' $R(15,85)$.' For the former contrast, we also test for the equality of the $b_{i}^{h}$ 's and $b_{i}^{\ell}$ 's. The significance level for the $\chi^{2}$ test for equality is reported in the column labelled 'Test for equality of $b^{h}$ and $b^{\ell} .{ }^{5}$ Finally, we also report the t-ratios for the tests that $\operatorname{Var}\left(b_{i}^{h}\right)=\operatorname{Var}\left(b_{i}^{\ell}\right)$, which is equivalent to the test for $\mathcal{R}$ equal 1 ; these are the numbers in parentheses. ${ }^{6}$

In almost all cases, we strongly reject the hypothesis that $b^{h}=b^{\ell}$. Interestingly, there are rejections on both sides of the null. In some industries, including food, lumber, paper, chemicals, petroleum, and fabricated metals, the estimated value of $\mathcal{R}$ is less than 1 , suggesting that the variance of the seasonals is smaller near a peak than near a trough. In other industries, including apparel, furniture, printing, nonelectrical and electrical machinery, and especially transportation, $\mathcal{R}$ exceeds 1 implying a positive correlation between the cycle and the variance of the seasonals. Finally, there is the case of rubber, leather, and instruments, where $\mathcal{R} \approx 1$, indicating no apparent correlation between the amplitude of the seasonals and the state of the business cycle.

To determine whether the interactions are economically meaningful, the Table also shows the fraction of the total variance that is due to seasonality - i.e. the $R^{2}$ from a regression of $q_{t}-\bar{q}_{t}$ on seasonal dummies alone. As emphasized by Barsky and Miron (1989), these series are very seasonal, implying that the interactions could lead to important shifts in the overall variability of the series. For example, an average of 91 percent of the variance of (detrended) food production can be explained by seasonal shifts. During a boom, however, seasonal swings are 26 percent smaller than during a recession.

Overall, we read Table 1 as providing substantial prima facie evidence for asser-

\footnotetext{
${ }^{5}$ We only report results for the test corresponding to the ' $(50,50)$ ' case. For the ' $(15,85)$ ' case, all of the p-values are 0.00 , with the exception of Tobacco which rises to 0.26 .

${ }^{6}$ We calculate the asymptotic standard error for the difference in the estimated variances from the covariance matrix of the estimated $b^{h}$ 's and $b^{\ell}$ 's using the delta method. The covariance matrix is computed using the Newey and West (1987) procedure with 24 lags.
} 
tion that there are important interactions between seasonal and cyclical variation in production. More importantly, these interactions suggest that standard seasonal adjustment procedures may miss certain systematic patterns in the data. For instance, the results imply that in some cases, faulty seasonal adjustment could lead policymakers to misread the strength of an expansion. Given the potential importance of this finding, the remainder of the paper attempts to explain why seasonal cycles and business cycles might be connected.

\section{Modeling Seasonal and Cyclical Interactions}

We develop a two-period model that describes the production problem faced by a set of monopolistically competitive firms in a particular industry. ${ }^{7}$ In this industry, both demand and the cost of production may fluctuate cyclically and seasonally.

An important feature of the model is that the representative firm may want to take advantage of the capacity that is idle during some seasons to help satisfy the demand in other seasons. In particular, during a business cycle boom a producer may smooth out seasonal variation in production by accumulating enough goods in lowdemand periods to satisfy part of the seasonal upswing in the high-demand periods. An essential predicate of the model is that cyclical influences on demand and cost persist across the seasons; in addition, capacity is costly to adjust at the cyclical frequency.

\subsection{The General Model}

Our treatment follows that of Rotemberg and Woodford $(1993),{ }^{8}$ in that we examine an industry that is composed of a large number of monopolistically competitive firms, indexed by $i$. This specification allows us to highlight the channels through which demand and cost interact. However, as we will show, many of the convenient assumptions used in solving the model could be relaxed. For instance, we could just

\footnotetext{
${ }^{7}$ We ignore the case of perfect competition throughout the analysis in order to allow for the possibility of increasing returns to scale in production.

${ }^{8}$ See the initial setup in Section 1 of their paper.
} 
as easily solve the production scheduling problem for a monopolist facing any smooth downward sloping demand function.

Firm $i$ produces output $Q_{i t}$ in period $t$; output of the industry as a whole is measured in terms of a composite good, whose quantity we denote $Q_{t}{ }^{9}$ The cost of producing $Q_{i t}$ is $C\left(Q_{i t} ; S_{t}, \lambda_{t}\right)$, where $S_{t}$ indexes the state of the season and $\lambda$ indexes the state of the business cycle. ${ }^{10}$ The form of this cost function is quite general. In particular, we allow the marginal cost curve to be either upward sloping or downward sloping, and we allow the cost function to shift both seasonally and cyclically.

Firms may carry inventories from one period to the next; we denote sales of firm $i$ as $X_{i t}$ and inventories as $I_{i t}$.

Firm $i$ faces the following inverse demand function:

$$
\frac{P_{i t}}{P_{t}}=D\left(\frac{X_{i t}}{X_{t}} ; S_{t}, \lambda_{t}\right)
$$

where $P_{i t}$ is the price of firms $i$ 's production in period $t, P_{t}$ is the price of the composite good in period $t$, and $X_{t}$ is aggregate sales of the composite good in period $t{ }^{11}$ Aside from assuming that it is monotonically decreasing in the relative quantity, we place no restrictions on the shape of $D$.

Finally, we assume that firms pay a storage cost $h\left(I_{i t}\right)$ to carry inventories from period $t$ into period $t+1$. We allow $I_{i t}$ to take on negative values (interpreted as backlogged orders), in which case $h\left(I_{i t}\right)$ should be thought of as the cost of stocking out. The storage/stockout cost is assumed to be increasing in the absolute value of the level of inventories, so that $h^{\prime}>0$ for $I>0$, and $h^{\prime}<0$ for $I<0$. It is also convenient to assume that $h(0)=0$.

\footnotetext{
${ }^{9}$ Formally, we could assume that there are a continuum of firms defined on a unit interval, and that the total quantity of the composite good produced in the industry is the integral over $i$ of individual firm production.

${ }^{10}$ This cost function can be derived using a variety of assumptions about the labor market. For instance, if, while making employment decisions, firms face a wage setting curve given by $w\left(L_{i t}\right)$, where $L_{i t}$ is labor hired, and the labor requirement to produce $Q_{i t}$ units of out put is $L\left(Q_{i t}\right)$, then the cost function is $C\left(Q_{i t}\right) \equiv w\left[L\left(Q_{i t}\right)\right] L\left(Q_{i t}\right)$. Inasmuch as there are many ways to interpret $w\left(L_{i t}\right)$, we do not need to commit ourselves to one particular model of the labor market, and instead work with $C\left(Q_{i t}\right)$ directly.

${ }^{11}$ The function $D$ can be derived from a number of different assumptions about market structure - e.g. Dixit and Stiglitz (1977).
} 
The firm chooses production, sales and inventories to solve:

$$
\max _{\left\{X_{i t}\right\},\left\{I_{i t}\right\}} \sum_{t=1}^{2} D\left(\frac{X_{i t}}{X_{t}} ; S_{t}, \lambda\right) X_{i t}-C\left(Q_{i t} ; S_{t}, \lambda\right)-h\left(I_{i t-1}\right)
$$

subject to

$$
\begin{aligned}
I_{i t}= & I_{i t-1}+Q_{i t}-X_{i t} \\
& I_{i 0} \text { and } I_{i 2} \text { given }
\end{aligned}
$$

where $I_{i 0}$ is the initial level of inventories and $I_{i 2}$ is the terminal level of inventories.

By convention, we assume that the second period is the high output season, so $Q_{i 2}>Q_{i 1} ;^{12}$ and that $\lambda$ is a positive measure of the business cycle, implying that $\frac{d Q_{i t}}{d \lambda}>0$.

At the optimum, marginal revenue must equal marginal cost in each period. In addition, the marginal cost of storage must equal the difference between the marginal cost of production in the two periods. Defining $h^{\prime}$ as the slope of the storage cost function, $C_{\boldsymbol{Q}}$ as marginal cost, and $g$ as marginal revenue, we write these first-order conditions as

$$
\begin{array}{r}
g\left(\frac{X_{i 1}}{X_{1}}, S_{1}, \lambda\right)-C_{Q}\left(Q_{i 1} ; S_{1}, \lambda\right)=0 \\
g\left(\frac{X_{i 2}}{X_{2}}, S_{2}, \lambda\right)-C_{Q}\left(Q_{i 2} ; S_{2}, \lambda\right)=0 \\
-C_{Q}\left(Q_{i 1} ; S_{1}, \lambda\right)+C_{Q}\left(Q_{i 2} ; S_{2}, \lambda\right)-h^{\prime}\left(I_{i 1}\right)=0
\end{array}
$$

where the marginal revenue function is defined by

$$
g\left(\frac{X_{i t}}{X_{t}}, S_{t}, \lambda\right)=D\left(\frac{X_{i t}}{X_{t}}, S_{t}, \lambda\right)+\frac{X_{i t}}{X_{t}} D^{\prime}\left(\frac{X_{i t}}{X_{t}}, S_{t}, \lambda\right)
$$

and $D^{\prime}$ is the derivative of demand with respect to sales.

\footnotetext{
${ }^{12}$ We could just as easily define the season with reference to the shift in demand and/or cost.
} 
An alternative way to write equation (8) (using the continuous time approximation) is:

$$
\frac{d g\left(X_{i t} / X_{t}, S, \lambda\right)}{d S}=h^{\prime}(I)
$$

This reorganization of the equation emphasizes the fact that if marginal revenue differs across seasons, firms will keep accumulating inventories to sell in the expensive season until the cost of storage becomes prohibitive. Since we have thus far placed no significant restrictions on the nature of fluctuations in marginal revenue, this insight is helpful because it tells us that we can infer some things about marginal revenue shifts by looking at how inventories are adjusted.

The model's predictions about how seasonal patterns change over the course of the business cycle are derived by totally differentiating either equation (6) or (7) with respect to both $S$ and $\lambda$ :

$$
Q_{S \lambda}=\frac{\frac{d^{2} g\left(X_{i t} / X, S, \lambda\right)}{d S d \lambda}-C_{Q S \lambda}-C_{Q Q S} Q_{\lambda}-Q_{S}\left(C_{Q Q Q} Q_{\lambda}+C_{Q Q \lambda}\right)}{C_{Q Q}}
$$

where $Q_{S}$ and $Q_{\lambda}$ are the seasonal and cyclical changes in production respectively.

Equation (11) describes the conditions under which seasonal fluctuations will vary with the state of the business cycle. The first term in the numerator of the right hand side of equation (11) measures the change in marginal revenue across seasons over the course of the business cycle. The remaining terms describe the curvature of the marginal cost function. Thus, in principle, variation in the seasonal pattern of production over the course of the business cycle could be due to either cost or demand factors. For instance, if demand is spread differently across seasons in booms and busts, then the seasonality of production should change over the business cycle.

Alternatively, to see why costs can matter, imagine a cyclical boom that increases demand across all seasons by an equal amount. In this case the demand shifts are not directly responsible for any connection between seasonal cycles and business cycles. Furthermore, if the marginal cost curve is linear, then the marginal cost of producing in the high demand state relative to producing in the low demand state will not be affected by expansion, so that the seasonality in production will not change. But, with a non-linear marginal cost curve, the relative cost will vary according to the 
state of demand, and hence, will depend on the location of the producer on the cost curve. Indeed, if the marginal cost curve is convex, then the relative cost of producing in the high demand season will be greater during a boom and the firm will smooth the seasonal in production by shifting more production into the low-demand season.

The preceding discussion describes the identification problem that one faces in trying to explain the interactions between business cycles and seasonal cycles - without some information about the nature of demand variation, $Q_{S \lambda}$ alone does not allow us to infer the shape of the cost function.

There are two ways to resolve this identification problem. One is to rely completely on additional theoretical restrictions to simplify equation (11). While this can be done in many ways, the easiest is to both adopt the standard convention of imposing a symmetric equilibrium and to be more specific about the source of seasonal or cyclical fluctuations. For instance, if marginal revenue is assumed to vary only seasonally or cyclically, but not both seasonally and cyclically, then $\frac{d^{2} g}{d S d \lambda}=0$ and demand shifts cannot be responsible for the interactions between the seasonal cycle and the business cycle. ${ }^{13}$ Similarly, if the marginal cost curve does not shift both seasonally and cyclically, some of the cost terms on the right hand side of (11) will be zero.

The alternative to using these sorts of theoretical restrictions is to estimate some of the terms on the right hand side of (11). At first glance, this appears not to have any advantages, since estimating demand or cost curves is notoriously difficult. But here we can exploit the connection between shifts in marginal revenue and changes in inventories. In particular, differentiating equation (8) with respect to $\lambda$ implies:

$$
\frac{d^{2} g\left(X_{i t} / X_{t}, S, \lambda\right)}{d S d \lambda}=h^{\prime \prime}(I) I_{\lambda}
$$

In other words, because inventories are used to arbitrage seasonal differences in the

\footnotetext{
${ }^{13}$ In a symmetric equilibrium, $\frac{d\left(X_{i t} / X_{i}\right)}{d \lambda}=\frac{d\left(X_{i t} / X_{t}\right)}{d S}=0$, which implies that $\frac{d^{2} g\left(X_{i t} / X_{i}, S, \lambda\right)}{d S d \lambda}=g_{S \lambda}$ - the derivative of marginal revenue with respect to the season and the cycle is independent of the level of demand. This means that, if we are willing to maintain that cyclical and seasonal shifts have no distributional consequences, then the channels through which demand shocks can affect production are limited considerably. In particular, since $g_{S \lambda}$ will be zero unless both seasonal cycles and business cycles are caused by demand shocks, the symmetry assumption, along with the assumption that either business cycles or seasonal cycles are cost based, would be enough to guarantee that the sign of $Q_{S \lambda}$ could be used to infer information about firms' cost functions.
} 
return to selling goods, equation (12) tells us how shifts in seasonal differences in marginal revenue over the business cycle will be reflected in inventory policy. Thus, we can bound the importance of demand factors without having to estimate the marginal revenue function directly.

Ultimately, we propose to resolve the identification problem by using both additional theoretical restrictions and empirical estimates. On theoretical grounds we assume that $h^{\prime \prime} \geq 0$. We are unaware of any work suggesting that marginal storage costs are declining, so this assumption should not be controversial. If, as a benchmark, one further assumes that storage costs are linear, then $h^{\prime \prime}$ is zero and the model tells us that shifts in marginal revenue cannot be responsible for any interactions between business cycles and seasonal cycles! In other words, if storage costs are linear, changes in the seasonal in production over the course of the business cycle must be due to the non-linearity of the marginal cost curve.

Assuming that $h^{\prime \prime}$ is strictly greater than zero, we must estimate of $I_{\lambda}$ to infer the effects of shifts in marginal revenue. If we observe that firms' inventory holdings do not shift with the business cycle, $I_{\lambda}=0$, this is a signal that the business cycle has not shifted the difference in marginal revenue across seasons, so any changes in production seasonals over the course of the business cycle must be due to non-linearities in the marginal cost curve.

Overall, we propose to reorganize (11) as:

$$
\left[\frac{h^{\prime \prime} I_{\lambda}}{C_{Q Q}}-Q_{S \lambda}\right]=\frac{C_{Q Q Q} Q_{S} Q_{\lambda}}{C_{Q Q}}+\frac{C_{Q S \lambda}}{C_{Q Q}}+\frac{C_{Q Q S}}{C_{Q Q}}+\frac{C_{Q Q \lambda}}{C_{Q Q}}
$$

Provided we can sign the left hand side of (13), we can learn about the sign of the sum of the four cost terms in (13). Surprisingly, the sign alone this tells us quite a bit about the shape of firms' cost curves.

For instance, suppose that the numerator and denominator had the same sign and $C_{Q Q}$ is also positive. In this case, one of the four terms in the numerator must be sufficiently positive to be the dominant factor. By definition $Q_{S}$ and $Q_{\lambda}$ are positive, so if $C_{Q Q Q}$ is the dominant positive term, the marginal cost curve would be convex it would look like a smooth version of the classic backward shaped 'L'. Alternatively, if the term involving $C_{Q Q S}$ is positive, this implies that the slope of marginal cost is 
increasing with the seasonal cycle. Similarly, a finding that the term involving $C_{Q Q \lambda}$ is non-negative implies that the slope of marginal cost is increasing with the business cycle. Both of these descriptions of the cost curve also amount to saying that the firm faces a certain type of capacity constraint.

Finally the sign of the right hand side of equation (13) could be determined by the term involving $C_{Q S \lambda}$. If $C_{Q S \lambda}$ is positive, then the change in slope of marginal cost across the seasons is bigger during a boom. Although this sort of shift may seem less intuitive or plausible than the other three explanations for why the right hand side of (13) could be positive, it still implies that the cost curve gets steeper in a particular way - i.e., that marginal cost is 'convex'. Thus, provided that $C_{Q Q}$ is positive, if right hand side of (13) is positive then firms face a marginal cost curve that becomes steeper as output expands - capacity constraints.

Logically it is also possible that (13) is positive because the numerator and denominator of the right hand side of (13) are both be negative. But, if both the numerator and denominator are negative, then firms would face returns that are increasing at any increasing rate. On theoretical grounds we find this description of technology to be highly implausible. Therefore, simply by establishing that the right hand side of (13) is positive we can determine both the shape and slope of the marginal cost curve.

The same sort of reasoning can be used to understand the implications of the right hand side of (13) being negative. In this case, if $C_{Q Q}$ is positive, then firms would be operating with a concave marginal cost function - i.e. the marginal cost function rises but is becoming less steep as output increases. Loosely speaking, this sort of flattening out of the marginal cost curve might be due to learning. But, regardless of the reason for the flattening out, this sort of technology will give firms an incentive to try to bunch their production.

Alternatively, the right hand side of (13) could be negative because the numerator is positive and the denominator is negative $\left(C_{Q Q}<0\right.$, but $\left.C_{Q Q Q}>0\right)$. In this case, marginal cost is downward sloping, but at a decreasing rate. Again, marginal costs flatten out in a way that gives firms an incentive to bunch production.

To summarize, the model shows precisely why decoding information contained in 
the sign of $Q_{S \lambda}$ requires information on which shocks generate seasonal cycles and business cycles. Fortunately, the importance of marginal revenue shocks can always be inferred from inventory patterns. (In some cases, determining the relevance of marginal revenue shocks might not even depend on using data on inventories.)

If we infer that demand shocks are not important, then the sign of $Q_{S \lambda}$ will identify the shape of the cost function. If $Q_{S \lambda}$ is positive, then the ratio of the second to the 'third' derivative of the cost function is negative and firms' marginal cost curves will be flattening out at higher levels of production. If $Q_{S \lambda}$ is negative, seasonal cycles would be smoothed in booms because firms face capacity constraints.

Conversely, if demand shifts are important then the sign of $Q_{S \lambda}$ will not identify the shape of the cost function. Instead, it becomes necessary to consider the signs of both $I_{\lambda}$ and $Q_{S \lambda}$ and in some cases it may not be possible to pin down the shape of the cost function. For instance, if firms hold fewer inventories going into a high demand season during a boom, i.e. $I_{\lambda}<0$, then finding that $Q_{S \lambda}$ is also negative does not unambiguously give us information about firms' cost functions. On the other hand, if firms bring more inventories into a high demand season during a boom, i.e. $I_{\lambda}>0$, then finding that $Q_{S \lambda}$ is also negative strongly suggests that firms face capacity constraints.

\section{Empirical Results}

The objective of this section is to measure the extent of the interactions between seasonal and cyclical fluctuations using 2-digit industry-level data on industrial production.

\subsection{The Estimating Equation and the Inference Issue}

Equations (6) and (7) can be used to derive an expression for production in each period as a function of the season and the stage of the business cycle:

$$
Q=Q(S, \lambda)
$$


Taking a second-order Taylor series approximation of $Q(\cdot, \cdot)$ about $\bar{Q}=Q(\bar{S}, \bar{\lambda})$, we have

$$
\begin{gathered}
Q-\bar{Q}=Q_{S}(S-\bar{S})+Q_{\lambda}(\lambda-\bar{\lambda})+\frac{1}{2} Q_{\lambda S}(S-\bar{S})(\lambda-\bar{\lambda}) \\
+\frac{1}{2} Q_{S S}(S-\bar{S})^{2}+\frac{1}{2} Q_{\lambda \lambda}(\lambda-\bar{\lambda})^{2}
\end{gathered}
$$

Since $S=S^{2}$, we can, without loss of generality, assume that $Q_{S S}=0$. Strictly speaking, equation (15) applies to the level of production; in line with previous work, however, we blur the distinction between levels and logs, and apply the equation to the logarithmic (rather than arithmetic) difference between $Q_{t}$ and $\bar{Q}_{t} \cdot{ }^{14}$

Interpreting $\ln \bar{Q}_{t}$ as a linear time trend plus a possibly nonstationary random variable, and reverting to the notation of Section 2 we have:

$$
q_{t}=\alpha t+\sum_{i=1}^{12} \sigma_{i} s_{i t}+\sum_{i=1}^{12} \rho_{i} s_{i t} \lambda_{t}+\delta \lambda_{t}^{2}+\epsilon_{t}
$$

where $s_{i t}$ and $\lambda_{t}$ are as defined in Section $2 ; \alpha, \sigma, \rho$ and $\delta$ are parameters; and $\epsilon_{t}$ is the random element of $\bar{q}_{t} \cdot{ }^{15}$ (Notice that by including a seasonal dummy variable for all twelve months it is not necessary to explicitly include either a constant or the level of $\lambda$ in (16), since these are just the averages of the $\sigma_{i}$ 's and $\rho_{i}$ 's respectively.)

Defining $\bar{\sigma}$ and $\bar{\rho}$ as the seasonal means of the $\sigma_{i}$ 's and $\rho_{i}$ 's we can rewrite (16) as

$$
\begin{aligned}
q_{t}= & \alpha t+\sum_{i=1}^{12}\left(\sigma_{i}-\bar{\sigma}\right)\left(s_{i t}-s_{12 t}\right)+\sum_{i=1}^{12}\left(\sigma_{i}-\bar{\sigma}\right) s_{12 t}+\bar{\sigma} \sum_{i=1}^{12} s_{i t} \\
& +\sum_{i=1}^{12}\left(\rho_{i}-\bar{\rho}\right)\left(s_{i t}-s_{12 t}\right) \lambda_{t}+\sum_{i=1}^{12}\left(\rho_{i}-\bar{\rho}\right) s_{12 t} \lambda_{t}+\bar{\rho} \sum_{i=1}^{12} s_{i t} \lambda_{t}+\delta \lambda_{t}^{2}+\epsilon_{t} \\
= & \alpha t+\sum_{i=1}^{12} \beta_{i} \mathcal{S}_{i t}+\sum_{i=1}^{12} \phi_{i} \mathcal{S}_{i t} \lambda_{t}+\delta \lambda_{t}^{2}+\epsilon_{t}
\end{aligned}
$$

where

$$
\beta_{i}=\sigma_{i}-\bar{\sigma}, \quad i=1, \cdots, 11
$$

\footnotetext{
${ }^{14}$ This can be justified by use of the approximation that $(Q / \bar{Q})-1 \approx \ln Q-\ln \bar{Q}$.

${ }^{15}$ Modeling the error in (16) as nonstationary is a more robust way of removing the trend from $q_{t}$ than the moving average estimates of $\bar{q}_{t}$ used in Section 2.
} 


$$
\begin{aligned}
\beta_{12} & =\bar{\sigma} \\
\phi_{i} & =\rho_{i}-\bar{\rho}, \quad i=1, \cdots, 11 \\
\phi_{12} & =\bar{\rho} \\
\mathcal{S}_{i t} & =s_{i t}-s_{12 t}, \quad i=1, \cdots, 11 \\
\mathcal{S}_{12 t} & =\sum_{i=1}^{12} s_{i t}=1 \quad \forall t .
\end{aligned}
$$

The fact that $\epsilon_{t}$ may be nonstationary leads us to estimate the first-difference of (17):

$$
\begin{gathered}
\Delta q_{t}=\tilde{\alpha}+\sum_{i=1}^{11} \beta_{i}\left(\mathcal{S}_{i t}-\mathcal{S}_{i t-1}\right)+\sum_{i=1}^{11} \phi_{i}\left(\lambda_{t} \mathcal{S}_{i t}-\lambda_{t-1} \mathcal{S}_{i t-1}\right) \\
+\bar{\rho} \Delta \lambda_{t}+\delta \Delta \lambda_{t}^{2}+\Delta \tilde{\epsilon}_{t}
\end{gathered}
$$

where $\tilde{\alpha}=\alpha+E_{0}\left(\Delta \epsilon_{t}\right)$ and $\Delta \tilde{\epsilon}_{t}=\Delta \epsilon_{t}-E_{0}\left(\Delta \epsilon_{t}\right) . E_{0}\left(\Delta \epsilon_{t}\right)$ is the drift in $\epsilon_{t}$.

Most of the hypotheses of interest can be addressed by considering the quantity:

$$
D_{i}=\frac{1}{2}\left(\beta_{i}+\phi_{i} \lambda\right)^{2}
$$

This is analogous to the square of the $b_{i}$ 's in equation (2) that are used in the computation of $\mathcal{R}$. If $D_{i}$ shrinks as $\lambda$ increases, then we can conclude that seasonals are smaller in booms, i.e. $Q_{S \lambda}<0$. To study this, we calculate

$$
d_{i}=\left.\frac{d D_{i}}{d \lambda}\right|_{\lambda=\bar{\lambda}}=\left(\beta_{i}+\phi_{i} \bar{\lambda}\right) \phi_{i}
$$

which simplifies to $d_{i}=\beta \phi_{i}$ since $\lambda$ is mean zero.

We examine three properties of $\mathrm{d}$, the vector of $d_{i} \cdot{ }^{16}$ First, we count the number of elements of $\mathbf{d}$ that are negative. Second, we test $H_{o}: \mathbf{d}=0$ against $H_{a}: \mathbf{d} \neq 0$. And, finally, we use Andrews (1994) directed Wald statistic to examine the test of $H_{o}: \mathbf{d}=0$ versus the restricted alternatives that $H_{a}: \mathbf{d}<0$. The first accords with $Q_{S \lambda}$ negative suggesting capacity constraints - steepening marginal cost, while the

\footnotetext{
${ }^{16}$ Using the fact that the $\beta_{i}$ 's and $\phi_{i}$ 's are deviations from means, we can calculate $\delta_{12}=-\sum_{i=1}^{11} \delta_{i}$ and $\phi_{12}=-\sum_{i=1}^{11} \phi_{i}$. This means that we can treat $\mathbf{d}$ as having twelve elements.
} 
Table 2: Results of the OLS Regression of Log Output on Seasonals and Seasonal/Cyclical Interactions Monthly 2-Digit Industrial Production, 1956:01 to 1994:01

\begin{tabular}{||l|c|c|c||}
\hline \hline \multicolumn{1}{|c|}{ Industry } & $\begin{array}{c}\text { Number of } \\
d_{i}^{\prime} s<0\end{array}$ & $\begin{array}{c}\text { p-value for } \\
H_{a}: \mathbf{d} \neq 0\end{array}$ & $\begin{array}{c}\text { p-value for } \\
H_{a}: \mathbf{d}<0\end{array}$ \\
\hline 20 Foods & 7 & 0.00 & 0.00 \\
21 Tobacco & 9 & 0.25 & 0.05 \\
22 Textiles & 7 & 0.00 & 0.11 \\
23 Apparel & 4 & 0.04 & 0.90 \\
24 Lumber & 8 & 0.01 & 0.21 \\
25 Furniture & 6 & 0.01 & 0.01 \\
26 Paper & 5 & 0.00 & 0.02 \\
27 Printing & 5 & 0.13 & 0.61 \\
28 Chemicals & 7 & 0.00 & 0.01 \\
29 Petroleum & 8 & 0.01 & 0.00 \\
30 Rubber & 5 & 0.03 & 0.46 \\
31 Leather & 6 & 0.00 & 0.10 \\
32 Clay, Glass and Stone & 4 & 0.00 & 0.11 \\
33 Primary Metals & 4 & 0.08 & 0.31 \\
34 Fabricated Metals & 8 & 0.00 & 0.01 \\
35 Nonelectrical Machinery & 7 & 0.01 & 0.12 \\
36 Electrical Machinery & 2 & 0.00 & 0.98 \\
37 Transportation & 3 & 0.00 & 0.74 \\
38 Instruments & 6 & 0.00 & 0.00 \\
39 Miscellaneous & 6 & 0.02 & 0.71 \\
\hline \hline
\end{tabular}

Results refer to estimation of equation (18). See the text for definitions and descriptions and Table 1 for a description of the data.

second implies $Q_{S \lambda}$ positive, suggesting that marginal cost flattens out.

\subsection{Ordinary Least Squares Results}

We estimate equation (18) using monthly two-digit industrial production data. Our first set of estimates, reported in Table 2, are based on defining $\lambda_{t}$ to be capacity utilization in total manufacturing, lagged one month, and estimating the covariance matrix of the coefficient estimates using the Newey and West (1987) procedure with 24 lags. ${ }^{17}$ For each industry except apparel, the sample runs from January 1956

\footnotetext{
${ }^{17}$ The use of aggregate capacity utilization as a regressor is valid if we assume that it accurately
} 
through January 1994. The seasonal in the apparel series changed dramatically in 1977 , so we truncate the sample for that industry in December 1976. The regression for the transportation industry includes dummy variables from September through December of 1970 to account for the auto strike.

The table reports results for the three hypotheses of interest. In the second column, we simply report the number of $d_{i}$ 's that are negative. In the third column of Table 2 we report the p-value for the test that all of the $d_{i}$ 's are zero. By and large, this hypothesis is overwhelmingly rejected, implying that virtually all of the industries' seasonals vary over the cycle. The fourth column presents the results for the p-value for the Andrews directed Wald test. ${ }^{18}$ In eight of the twenty cases we can reject at the five-percent level or better the hypothesis of no interaction in favor of the hypothesis that seasonals contract in a boom. But again, transportation is an outlier, in that its seasonals do not systematically shrink.

Figure 1 plots the estimated seasonal coefficients from equation (18) for four industries: Food, Petroleum, Electrical Machinery and Transportation Equipment. The bars represent the $\beta_{i}$ 's, the average seasonals; the solid line is $\beta_{i}+\phi_{i} \lambda_{h}$, the seasonal of a typically high point of the business cycle; and the dashed line plots $\beta_{i}+\phi_{i} \lambda_{\ell}$, the seasonal in at a typically low point of the cycle. $\lambda_{h}$ and $\lambda_{\ell}$ are, respectively, the means of $\lambda_{t}$ above the 85 th percentile and below the 15 th percentile of $\lambda_{t}$.

Food and Petroleum provide striking examples of smoothing at the seasonal frequency when output is high. By contrast, production of Transportation Equipment and Electrical Machinery provide examples of the opposite phenomenon. For Transportation, the added variability is due to the exaggerated reduction in production during July, August and September - perhaps reflecting a tendency of automakers to concentrate their annual shutdown more tightly around the end of the model year when demand is strong. Interestingly, the same sort of bunching seems to occur in

measures the entirety of the common movement in production across industries. When this is true, the error in the regression is uncorrelated with the aggregate indicator. The use of a virtually contemporaneous measure of activity is consistent with our attempt to calculate responses that take capacity as fixed.

${ }^{18}$ Calculations of Andrews test requires several choices. We set the weighting factor $c$ equal to plus infinity, the number of repetitions for the Geweke-Hajivassiliou-Keane algorithm to 2500 and the number of quantile repetitions to 5000 . 
Figure 1: Comparison of Seasonals over the Cycle for Selected Industries
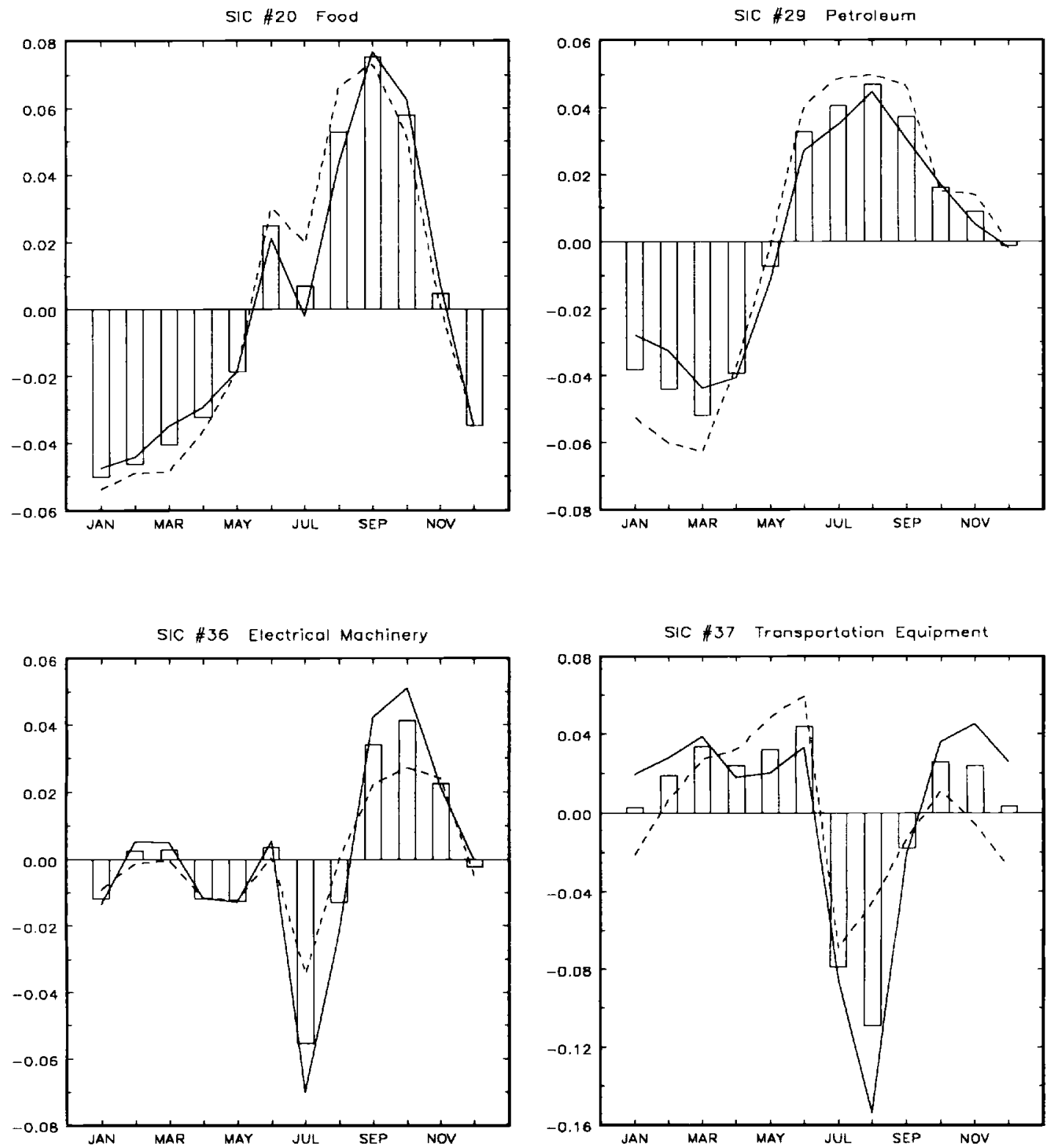

The bars are average seasonals, the solid lines are the seasonals during a peak, defined as average capacity utilization conditional on utilization being in the top fifteen percent of the distribution, and the dashed lines are the seasonals during a trough, defined as average capacity utilization conditional on utilization being in the bottom fifteen percent of the distribution. 
Table 3: OLS Regression Implied Variance of Seasonal Means During High and Low Levels of Aggregate Activity

Monthly 2-Digit Industrial Production, 1956:01 to 1994:01

\begin{tabular}{||l|c|c||l|c|c||}
\hline \hline \multicolumn{1}{|c|}{ Industry } & $\mathcal{R}(50,50)$ & $\mathcal{R}(15,85)$ & Industry & $\mathcal{R}(50,50)$ & $\mathcal{R}(15,85)$ \\
\hline 20 Foods & 0.90 & 0.81 & 30 Rubber & 1.24 & 1.42 \\
& $(-1.33)$ & $(-1.53)$ & & $(1.00)$ & $(0.814)$ \\
\hline 21 Tobacco & 0.81 & 0.67 & 31 Leather & 1.20 & 1.39 \\
& $(-2.11)$ & $(-2.83)$ & & $(1.15)$ & $(0.91)$ \\
\hline 22 Textiles & 1.02 & 1.03 & 32 Clay, Glass & 0.97 & 0.95 \\
& $(0.19)$ & $(0.15)$ & and Stone & $(-0.21)$ & $(-0.22)$ \\
\hline 23 Apparel & 1.16 & 1.32 & 33 Primary & 1.25 & 1.51 \\
& $(0.91)$ & $(0.72)$ & Metals & $(0.58)$ & $(0.50)$ \\
\hline 24 Lumber & 0.85 & 0.73 & 34 Fabricated & 0.79 & 0.66 \\
& $(-1.28)$ & $(-1.55)$ & Metals & $(-1.07)$ & $(-1.58)$ \\
\hline 25 Furniture & 1.08 & 1.13 & 35 Nonelectrical & 0.91 & 0.84 \\
& $(0.61)$ & $(0.56)$ & Machinery & $(-0.33)$ & $(-0.43)$ \\
\hline 26 Paper & 0.95 & 0.91 & 36 Electrical & 1.96 & 3.63 \\
& $(-0.39)$ & $(-0.44)$ & Machinery & $(4.09)$ & $(1.83)$ \\
\hline 27 Printing & 1.08 & 1.16 & 37 Transportation & 1.89 & 2.89 \\
& $(0.46)$ & $(0.41)$ & & $(3.13)$ & $(2.08)$ \\
\hline 28 Chemicals & 0.77 & 0.61 & 38 Instruments & 1.02 & 1.02 \\
& $(-1.46)$ & $(-2.02)$ & & $(0.06)$ & $(0.05)$ \\
\hline 29 Petroleum & 0.67 & 0.47 & 39 Miscellaneous & 1.05 & 1.09 \\
& $(-2.32)$ & $(-3.52)$ & & $(0.30)$ & $(0.27)$ \\
\hline \hline
\end{tabular}

The table reports the ratio of the variance of the $\left(\beta_{i}+\phi_{i} \lambda_{h}\right)$ 's to the $\left(\beta_{i}+\phi_{i} \lambda_{l}\right)$ 's, where $\lambda_{h}$ and $\lambda_{\ell}$ are the means of the aggregate indicator from the percentage of the distribution at the top of the column. Values in parentheses are t-ratios for the test that the variance ratio equals one.

Electrical Machinery, another industry where short product life cycles might make learning considerations important.

We can use the regression results to compute the ratio of the variance of the seasonals during high and low points of the cycle, and quantify the differences shown in Figure 1. The column labeled ' $(50,50)$ ' in Table 3 reports the results for the case in which $\lambda_{h}$ and $\lambda_{\ell}$ are the means of the upper and lower 50 percent of the distribution of $\lambda_{t}$, while the column labeled ' $(15,85)$ ' reports the results for the case in which $\lambda_{h}$ and $\lambda_{\ell}$ are defined using the 85 th and 15 th percentiles.

The results are very similar to those in Table 1 . In fact, the correlation between 
the Table 1 and Table 3 point estimates is 0.95 for the $(50,50)$ case and 0.79 for the $(15,85)$ case. There are a few cases, however, including Paper and 'Miscellaneous,' where the regressions suggest that there is no distinct decrease in the variability of the seasonals but the simple calculations do; and Nonelectrical Machinery, in which the opposite occurs. ${ }^{19}$

\subsection{Two-Stage Least Squares Results}

Thus far, we have used total manufacturing capacity utilization as the measure of the cycle. But both the intuition of Section 2 and the model of Section 3 suggest that it is not aggregate activity that is important for seasonals, but whether an industry is experiencing a boom. While we feel (reasonably) comfortable assuming that aggregate manufacturing capacity utilization is exogenous to any given 2-digit industry, the same cannot be said for own-industry utilization. Therefore, when we substitute own-industry capacity utilization for aggregate manufacturing capacity in estimating equation (18), we instrument for it using aggregate capacity utilization.

Table 4 reports results based on this procedure, using aggregate and squared aggregate capacity utilization as instruments. As we did in producing Table 2, we lag all measures of capacity by one month. It is comforting to see that, with the exception of Petroleum where the p-values have suddenly grown, the results are very similar to those in Table $2 .^{20}$ The results in Table 3 are also robust to estimating the regression by two-stage least squares.

\subsection{Inventories}

Finally, we return to the question of whether the seasonal and cyclical interactions are more likely to be due to shifts in demand or to the shape of the cost function. Recall, from Section 3, that firms could choose to damp the seasonal in production when the economy is strong solely because marginal revenue increases by less in the

\footnotetext{
${ }^{19}$ Again, the importance of the cyclical variation in seasonals can be gauged by noting that the output series have substantial seasonality. The $R^{2}$ s of the regressions of $\Delta q_{t}$ on seasonals alone are roughly equal to those reported in Columns 2 and 6 of Table 1.

${ }^{20}$ The results for Petroleum confirm those in the OLS case when the $\lambda_{t}^{2}$ term is omitted.
} 
Table 4: Results of the 2SLS Regression of Log Output on Seasonals and Seasonal/Cyclical Interactions

Monthly 2-Digit Industrial Production, 1956:01 to 1994:01

\begin{tabular}{||l|c|c|c|}
\hline \hline \multicolumn{1}{|c|}{ Industry } & $\begin{array}{c}\text { Number of } \\
d_{i}^{\prime} s<0\end{array}$ & $\begin{array}{c}\text { p-value for } \\
H_{\boldsymbol{a}}: \mathbf{d} \neq 0\end{array}$ & $\begin{array}{c}\text { p-value for } \\
H_{\boldsymbol{a}}: \mathbf{d}<0\end{array}$ \\
\hline 20 Foods & 8 & 0.02 & 0.01 \\
21 Tobacco & 9 & 1.00 & 0.28 \\
22 Textiles & 7 & 0.05 & 0.37 \\
23 Apparel & 7 & 0.00 & 0.00 \\
24 Lumber & 9 & 0.02 & 0.03 \\
25 Furniture & 6 & 0.00 & 0.01 \\
26 Paper & 5 & 0.00 & 0.00 \\
27 Printing & 6 & 0.13 & 0.23 \\
28 Chemicals & 7 & 0.01 & 0.09 \\
29 Petroleum & 3 & 1.00 & 0.89 \\
30 Rubber & 5 & 0.00 & 0.01 \\
31 Leather & 7 & 0.44 & 0.27 \\
32 Clay, Glass and Stone & 4 & 0.01 & 0.24 \\
33 Primary Metals & 8 & 0.00 & 0.00 \\
34 Fabricated Metals & 8 & 0.00 & 0.09 \\
35 Nonelectrical Machinery & 8 & 0.00 & 0.01 \\
36 Electrical Machinery & 4 & 0.00 & 0.65 \\
37 Transportation & 6 & 0.00 & 0.80 \\
38 Instruments & 6 & 0.05 & 0.12 \\
39 Miscellaneous & 6 & 0.05 & 0.88 \\
\hline \hline
\end{tabular}

Results refer to estimation of equation (18). See the text for definitions and descriptions and Table 1 for a description of the data. 
high-demand season during a boom - i.e., because $\frac{d^{2} g\left(X_{i t} / X_{t}, S, \lambda\right)}{d S d \lambda}$ is negative. As shown by equation (12), the sign of this demand effect can be inferred from inventory behavior. Intuitively, if shifts in marginal revenue are important, then firms will use inventories to exploit differences in demand elasticities across periods. Therefore, we can ascertain the importance of demand fluctuations by studying the sensitivity of seasonal inventory patterns to the stage of the business cycle, $I_{\lambda}$.

In the model of Section 3, inventories are used to shift output from low to high production periods. As a result, $I_{\lambda}$ measures the impact of a boom on the level of inventories that are carried into a high production season. So, $I_{\lambda}$ is positive when a boom causes an abnormal buildup of inventories prior to a high production season.

Using a Taylor-series expansion for inventories that is analogous to the one described in our study of production seasonals suggests the following equation:

$$
\begin{gathered}
\Delta I_{t}=\gamma+\sum_{i=1}^{11} \mu_{i}\left(\mathcal{S}_{i t}-\mathcal{S}_{i t-1}\right)+\sum_{i=1}^{11} \omega_{i}\left(\lambda_{t} \mathcal{S}_{i t}-\lambda_{t-1} \mathcal{S}_{i t-1}\right) \\
+\bar{\eta} \Delta \lambda_{t}+\nu \Delta \lambda_{t}^{2}+\Delta \tilde{u}_{t}
\end{gathered}
$$

The coefficients $\omega_{i}$ measure the extent to which inventory seasonals are influenced by the business cycle. Since inventories are typically measured at the end of a period, our interest is in the correlation between $\omega_{i} \lambda$ and the production seasonal in the following month, $\left(\beta_{i+1}+\phi_{i+1} \lambda\right)$, evaluated at a typical measure of $\lambda$. We equate the sign of $I_{\lambda}$ with the sign of this correlation.

Table 5 presents the results obtained by jointly estimating (19) and (18), using NSA real inventory data calculated by summing final goods and work-in-process inventories [see Blinder (1986, pg. 434)]. ${ }^{21}$ The estimates of the correlation reported in the Tables are calculated for $\lambda$ set equal to 3.7 over its sample mean of 81.6 - the mean of the top half of the capacity utilization data. Our results show that seven of the twenty correlations have t-ratios greater than 1.65 in absolute value, with three of these positive and four negative. For the remaining thirteen industries, the correlation is statistically indistinguishable from zero. Consequently, in only four of the

\footnotetext{
${ }^{21}$ Since the BEA does not produce NSA real inventory data, we follow Miron and Zeldes (1988) and construct them by calculating the seasonal factors from ratio of the NSA to the SA nominal inventory data and then applying these ratios to the SA real inventory data.
} 
Table 5: Cyclical Change in Inventory Seasonals Monthly 2-Digit Industry Data, 1958:01 to 1993:04

\begin{tabular}{||l|c||l|c||}
\hline \hline Industry & Sign of $I_{\lambda}$ & Industry & Sign of $I_{\lambda}$ \\
\hline 20 Foods & 0.38 & 30 Rubber & -0.71 \\
& $(2.01)$ & & $(4.71)$ \\
\hline 21 Tobacco & 0.43 & 31 Leather & 0.00 \\
& $(2.96)$ & & $(0.02)$ \\
\hline 22 Textiles & 0.29 & 32 Clay, Glass & -0.56 \\
& $(1.38)$ & and Stone & $(1.20)$ \\
\hline 23 Apparel & 0.25 & 33 Primary & -0.09 \\
& $(1.07)$ & Metals & $(0.46)$ \\
\hline 24 Lumber & 0.45 & 34 Fabricated & -0.64 \\
& $(1.75)$ & Metals & $(3.02)$ \\
\hline 25 Furniture & 0.13 & 35 Nonelectrical & 0.30 \\
& $(0.41)$ & Machinery & $(0.58)$ \\
\hline 26 Paper & -0.09 & 36 Electrical & -0.59 \\
& $(0.37)$ & Machinery & $(2.38)$ \\
\hline 27 Printing & 0.42 & 37 Transportation & 0.15 \\
& $(1.00)$ & & $(1.51)$ \\
\hline 28 Chemicals & -0.48 & 38 Instruments & 0.02 \\
& $(2.35)$ & & $(0.05)$ \\
\hline 29 Petroleum & -0.36 & 39 Miscellaneous & 0.13 \\
& $(1.53)$ & & $(0.27)$ \\
\hline \hline
\end{tabular}

The table reports the estimated correlation between $\omega_{i} \lambda$ and $\beta+\phi_{i} \lambda$, with $\lambda$ equal to the mean of the top 15 percent of the capacity utilization data, along with the t-ratio of the correlation. Standard errors are computed by stacking equations (18) and (19), with the covariance matrix of the estimated coefficients calculated using Newey and West (1987) with 24 lags. 
cases is it possible that demand shifts might be responsible for seasonals shrinking in a boom.

Combining the information in Tables 2 through 5 it is possible to classify industries according to what our tests suggest about the shape of their cost curves. For one set industries, including Food, Tobacco, Lumber, and Petroleum, the evidence suggest that firms face capacity constraints. In these industries the seasonality in production falls during a boom. Conversely, in the Electrical Machinery, Transportation and Rubber industries, production and inventory patterns suggest that marginal production costs flatten out as output rises. In these industries, the seasonality in production increases during booms. For a third set of industries, including Printing, Chemicals and Fabricated Metals, our estimates indicate that demand shocks alone could account for any interactions between business cycles and seasonal cycles. Finally, in the remaining industries we find that seasonal cycles and business cycles interact, but not in a way that can be neatly summarized. For these industries, we can detect a non-linearity but cannot be sure whether it comes because of cost or demand shifts.

\section{Conclusion}

In this paper we uncover several new facts about the business cycle. In particular, we show that there are significant interactions between the seasonal and cyclical variation in production for many industries. To interpret these findings we develop a model showing that the existence of an interaction depends on either nonlinearity in marginal cost, or specific combinations of seasonal and cyclical movements in cost and marginal revenue. More precisely, we show that seasonals will be smaller during booms, all else equal, if firms face marginal cost curves that are convex upward (i.e. their cost function have positive third derivatives).

Overall, our regression results suggest that industries fall into roughly four categories. For one group of industries, including Food, Tobacco, Lumber, and Petroleum, the evidence suggest that firms face capacity constraints. In these industries the seasonality in production falls during a boom. Conversely, in the Electrical Machinery, 
Transportation and Rubber industries, production and inventory patterns suggest that they may benefit from some form of learning-by-doing which results in marginal costs flattening out as production increases. In these industries, the seasonality in production rises during booms. Interestingly, in Transportation, most of the increased variability comes around the traditional time of annual model change-over, and so may reflect the non-convexities of the sort studied by Ramey (1991) or Bresnahan and Ramey (1992). Although the richness of the transportation industry data has led many researchers to focus on this industry, our results suggest that it is somewhat atypical and we caution against extrapolating from results regarding this single industry to the likely behavior of the economy as a whole.

For the other manufacturing industries, our results are less clear-cut. For one set, including Printing, Chemicals and Fabricated Metals, our estimates indicate that demand shocks alone could account for any interactions between business cycles and seasonal cycles. Thus, there is no way to learn anything about these industries' cost functions from our tests. Finally, for the remaining industries we find that seasonal cycles and business cycles interact, but not in a way that can be neatly summarized. For these industries, we can detect a non- linearity but cannot be sure whether it comes because of cost or demand shifts.

A number of questions warrant further study. First, how does one conduct seasonal adjustment when seasonals interact with the business cycle? Standard seasonal adjustment procedures are not appropriate in such circumstances. Krane and Wascher (1991), building on work of Stock and Watson $(1989,1991)$, develop a framework that addresses some of the statistical difficulties involved in dealing with such interactions, though in a multivariate framework. But there still remains the basic issue of whether the interaction term should be treated as 'seasonal' or 'cyclical,' and, at a more fundamental level, whether seasonal adjustment makes sense at all when seasonals and cycles do not neatly decompose.

Second, how can we test more directly our assertion that sluggish adjustment of capacity is the key element of the mechanism producing the seasonal/cyclical interactions? One approach (that we plan to pursue) would be to study intensively a few carefully chosen industries. In particular, by focusing on cross-industry differences 
in lead times for expanding plant size, as well as differences in the size of seasonal and cyclical swings, we hope to design more powerful tests of the capacity constraint hypothesis. 


\section{REFERENCES}

Andrews, Donald W. K. 'Hypothesis Testing with a Restricted Parameter Space,' Cowles Foundation Discussion Paper No. 1060R, Yale University, June 1994.

Barsky, Robert B. and Jeffrey A. Miron, 'The Seasonal Cycle and the Business Cycle,'Journal of the Political Economy 97 (June 1989) 503-535.

Beaulieu, J. Joseph, Jeffrey K. MacKie-Mason, and Jeffrey A. Miron, 'Why Do Countries and Industries with Large Seasonal Cycles Also Have Large Business Cycles?' Quarterly Journal of Economics 107 (May 1992) 621-656.

Beaulieu, J. Joseph and Jeffrey A. Miron, 'The Seasonal Cycle in U.S. Manufacturing,' Economics Letters, 37 (1991) 115-118.

and , 'A Cross Country Comparison of Seasonal Cycles and Business Cycles,' Economic Journal 102 (July 1992) 772-788.

Blanchard, Olivier J., 'The Production and Inventory Behavior of the American Automobile Industry,' Journal of Political Economy 91 (June 1983) 365-400.

Blinder, Alan S., 'Can the Production Smoothing Model of Inventory Behavior Be Saved?' Quarterly Journal or Economics 101 (August 1986) 431-453.

and Louis J. Maccini, 'Taking Stock: A Critical Assessment of Recent Research on Inventories,' Journal of Economic Perspectives 5 (Winter 1991) 73-96.

Bresnahan, Timothy F. and Valerie A. Ramey, 'Output Fluctuations at the Plant Level,' NBER Working Paper No. 4105, June 1992.

Cooper, Russell and John Haltiwanger, 'The Macroeconomic Implications of Machine Replacement: Theory and Evidence,' American Economic Review 83 (June 1993) $360-382$.

Dixit, Avinash and Joseph E. Stiglitz, 'Monopolistic Competition and Optimum Product Diversity,' American Economic Review 67 (June 1977) 297-308.

Fair, Ray C., 'The Production Smoothing Model is Alive and Well,' Journal of Monetary Economics 24 (November 1989) 353-370.

Ghysels, Eric 'On Seasonal Asymmetries and Their Implications for Stochastic and Deterministic Models of Seasonality,' mimeo., University of Montreal (1991).

Hall, Robert E. Booms and Recessions in a Noisy Economy New Haven, Conn.: Yale University Press, 1991.

Kashyap, Anil K and David W. Wilcox, 'Production and Inventory Control at the General Motors Corporation During the 1920s and 1930s,' American Economic Review 83 (June 1993) 383-401.

Krane, Spencer D., 'Induced Seasonality and Production-Smoothing Models of Inventory Behavior,' Journal of Econometrics 55 (January-February 1993) 135-168. 
and Steven N. Braun, 'Production Smoothing Evidence from Physical-Product Data,' Journal of Political Economy 99 (June 1991) 558-581.

and William Wascher, 'Cyclical Sensitivity of Seasonality in U.S. Employment,' mimeo., Board of Governors of the Federal Reserve, December 1991.

Miron, Jeffrey A. and Stephen P. Zeldes, 'Seasonality, Cost Shocks, and the Production Smoothing Model of Inventories,' Econometrica 56 (July 1988) 877-908.

and

'Production, Inventories, and Sales: An Identity that Doesn't Add Up,' Journal of Monetary Economics 24 (July 1989) 31-51.

Newey, Whitney K. and Kenneth D. West, 'A Simple, Positive Definite, Heteroskedasticity and Autocorrelation Consistent Covariance Matrix,' Econometrica 55, May 1987, 703-708.

Ramey, Valerie A. 'Non-Convex Costs and the Behavior of Inventories,' Journal of Political Economy 99 (April 1991) 306-334.

Rotemberg, Julio J. and Michael Woodford, 'Dynamic General Equilibrium Models with Imperfectly Competitive Product Markets,' N.B.E.R. Working Paper No. 4502, October 1993.

Stock, James H. and Mark W. Watson, 'New Indexes of Coincident Indicators' NBER Macroeconomics Annual 1989, 351-394.

and

'A Probability Model of the Coincident Economic Indicator,' in Kajal Lahiri and Geoffrey H. Moore, eds. Leading Economic Indicators: New Approaches and Forecasting Records, Cambridge: Cambridge University Press, 1991.

West, Kenneth D., 'A Variance Bounds Test of the Quadratic Inventory Model,' Journal of Political Economy 94 (April 1986) 374-401. 